Analytical Methods

\title{
Study of the influence of maceration time and oenological practices on the aroma profile of Vranec wines
}

\author{
Violeta Ivanova Petropulos ${ }^{\mathrm{a}, *}$, Elena Bogeva ${ }^{\mathrm{b}, \mathrm{c}}$, Trajče Stafilov $^{\mathrm{d}}$, Marina Stefova ${ }^{\mathrm{d}}$, Barbara Siegmund ${ }^{\mathrm{e}}$, \\ Nicole Pabi ${ }^{\mathrm{e}}$, Ernst Lankmayr ${ }^{\mathrm{e}}$ \\ ${ }^{a}$ University Goce Delčev, Faculty of Agriculture, Krste Misirkov bb, 2000 Štip, Macedonia \\ ${ }^{\mathrm{b}}$ Ss. Cyril and Methodius University, Institute of Agriculture, Aleksandar Makedonski bb, 1000 Skopje, Macedonia \\ ${ }^{\mathrm{c}}$ Elenov Winery, 1422 Demira Kapija, Macedonia \\ ${ }^{\mathrm{d}}$ Ss. Cyril and Methodius University, Faculty of Natural Sciences and Mathematics, Institute of Chemistry, Arhimedova 5, 1000 Skopje, Macedonia \\ ${ }^{\mathrm{e}}$ Graz University of Technology, Institute of Analytical Chemistry and Food Chemistry, Graz, Stremayrgasse 9/II, A8010 Graz, Austria
}

\section{A R T I C L E I N F O}

\section{Article history:}

Received 3 November 2012

Received in revised form 7 April 2014

Accepted 27 May 2014

Available online 5 June 2014

\section{Keywords:}

Aroma

Wine

Vranec

Maceration time

Enzyme

Oak chips

HS-SPME-GC-MS

\begin{abstract}
A B S T R A C T
Vranec is one of the most important red grape varieties in Republic of Macedonia, grown in all vineyards, mostly in the Tikveš wine region. In this study, Vranec wines produced with different maceration times $(4,7,14$ and 30 days) in presence of enzyme and oak chips during fermentation were studied in order to determine the influence of vinification conditions on the aroma profile. The volatile compounds were determined using headspace solid phase microextraction (HS-SPME) with a PDMS/Carboxen/DVB fibre, coupled with gas chromatography-mass spectrometry (GC-MS). In total 63 aroma compounds were detected revealing a complex aroma profile of Vranec wines composed of esters, alcohols, fatty acids, aldehydes, ketones and sulphur compounds. The content of aroma compounds was related mostly to maceration time, observing increased relative amount of alcohols, esters and fatty acids from the fourth to seventh day of maceration and the presence of oak chips during the fermentation enhanced their formation. The Student-Newman-Keuls test has been applied to ascertain possible significant differences between the studied wines, and principal component analysis has been employed, showing separation and grouping of the wines according to maceration time and oak chips treatment.
\end{abstract}

(C) 2014 Elsevier Ltd. All rights reserved.

\section{Introduction}

Wine aroma is a one of its most important characteristics produced by a complex balance of different chemical classes of volatile compounds, belonging to higher alcohols, esters, aldehydes, lactones, terpenes, $\mathrm{C}_{13}$-norisoprenoids, volatile phenols, fatty acids, carbonyls, sulphur and nitrogen compounds. More than 1000 aroma compounds with different polarities, volatilities and odour impact have been indentified in wines (Ivanova, Vojnoski, \& Stefova, 2012; Mendes, Gonçalves, \& Câmara, 2012; Perestrelo, Caldeira, Rodrigues, \& Câmara, 2008). In fact, the main aroma compounds in wine are higher aliphatic alcohols, ethyl esters and acetates. These compounds, present in the highest concentrations, are mainly formed from the yeast metabolism during the alcoholic fermentation. Their concentration in wine also depends on grape

\footnotetext{
* Corresponding author. Address: University Goce Delčev, Faculty of Agriculture, Krste Misirkov bb, 2000 Štip, Macedonia. Tel.: +389 32550 639; fax: +389 32390 700.

E-mail address: violeta.ivanova@ugd.edu.mk (V.I. Petropulos).
}

variety, light intensity, temperature, soil, climate, degree of maturation, cultivation practices etc. (Bureau, Razungles, \& Baumes, 2000; Lee et al., 2007; Skinkis, Bordelon, \& Butz, 2010; Zoecklein, Wolf, Marcy, \& Jasinski, 1998), as well as on prefermentative practises, many winemaking processes, such as, maceration, yeast strain, addition of enzyme preparations, wood chips, fermentation temperature, wine clarification, etc. (Bureau et al., 2000; Hernandez Orte, Guitart, Ferreira, Gracia, \& Cacho, 1998; Jackson \& Lombard, 1993; Zoecklein et al., 1998). Furthermore, wine ageing under different conditions may have influence on aroma profile generating volatiles that could decline the wine aroma quality.

Maceration is a very important phase in the production of high quality red wines which leads to increased colour stability and improved taste and flavour as well as overall better wine quality. During maceration, the content of aroma compounds increases due to the extraction of aromatic components from the grape skins. On the other hand, during maceration, alcoholic fermentation is carried out by the yeasts generating an increasing fraction of the volatile compounds in wine. At the beginning of fermentation, during the first 2-3 days, non-Saccharomyces cerevisiae yeasts, with 
lower sensitivity to alcohol, are present in the must, but afterwards, they decline rapidly, being replaced by the $S$. cerevisiae yeasts which are dominant until the end of fermentation. These yeast species generate a wide range of volatile and non-volatile compounds which determine the wine quality (Romano, Fiore, Paraggio, Caruso, \& Capece, 2003).

During winemaking, different oenological products could be used. Thus, enzymes are commonly used to improve the most important characteristics of wine, such as colour and aroma (Bautista-Ortín, Martínez-Cutillas, Ros-García, López-Roca, \& Gómez-Plaza, 2005; Castro-Vázquez, Pérez-Coello, \& Cabezudo, 2002; Revilla \& GonzálezSan José, 2003). Enzymes are complex proteins produced by living cells, which promote specific biological reactions acting as catalysts, and are mainly used to increase clarification and improve filtration of wine. Furthermore, enzymes are used to increase the colour and tannin extraction, to improve complexity, mouthfeel and stability as well as to release aroma compounds (Armada, Fernández, \& Falqué, 2010). Pectinases are the main enzymes used in winemaking, which could naturally occur in grapes or could be found as commercial preparations. Other enzyme groups, commercially available, are hemicellulases, glucanases and glycosidases. Enzymes may be added to the must during the pellicle maceration phase (called maceration enzymes) or during the clarification of the must or wine (called clarification enzymes).

Usage of oak wood is one of the traditional winemaking practices, positively affecting the sensorial and chemical quality of wine. In fact, the main roles of the wood are to improve the intensity and complexity of flavour and aroma of wines, to reduce the astringency and bitterness, to stabilize the colour and decrease the vegetative herbaceous aromas (Bozalongo, Carrillo, Fernándet Torroba, \& Tena, 2007; Garde Cerdán, Torrea Goñi, \& Ancín Azpilicueta, 2004; Macedo et al., 2008; Rayne, Sheppard, Di Bello, \& Eggers, 2011). Furthermore, using alternative techniques, such as use of oak chips, allows fermentation in stainless tanks, obtaining wines with decreased astringency and bitterness, similar like those fermented in barrels (Rodríguez-Bencomo, Ortega-Heras, \& Pérez-Magariño, 2010).

In addition, the variety of grape considerably determines the aroma of the wine due to the persistence of certain compounds present in the grape and compounds which are formed throughout the entire vinification process. Vranec is a grape variety mainly used for production of high quality red wines, mainly planted in the Tikveš wine region, the most famous region for vine growing and winemaking, where more than $80 \%$ of the Macedonian vineyards are located. It is high yielding, producing deep coloured fruit. The wines have intense dark red, ruby colour, rich in polyphenols (Ivanova, Stefova, \& Chinnici, 2010; Ivanova et al., 2011; Ivanova et al., 2012).

But, its aroma profile has not been thoroughly characterized yet. In fact, there is only one paper about the volatile profile of Macedonian and Hungarian wines, including the Vranec wine (Ivanova et al., 2013), whereas commercial wines have been analysed and compared. In this study, the main volatile components making the aroma profile of this local red wine were characterized for the first time, but since results were not conclusive, additional studies have to be performed.

Therefore, this paper is focussed on the identification of the volatiles of Vranec, and then, more thoroughly on the study of influence of the different vinification techniques on the content and changes of different aroma compounds in these wines. For that purpose, an HS-SPME method for sample preparation, coupled with GC-MS technique was applied for analysis of the wines in order to identify and quantify the presence of different groups of aroma compounds, including alcohols, esters, fatty acids, aldehydes, ketones, sulphur compounds and other compounds. The influence of different oenological practices, such as maceration time and addition of enzyme and oak chips in the grape mash during fermentation, on the content of aroma compounds in the wines, was studied. This study provides important and systematically collected data about the aroma profile of this variety in order to find the appropriate technological practices that ensure wine with highest content of aromatic compounds influencing and improving its quality.

\section{Materials and methods}

\subsection{Grapes}

Grapes from Vranec variety, Vitis vinifera L., cultivated at Disan location, Tikveš wine region, R. Macedonia, were harvested in October, 2010, at optimal maturity (22.1 Brix). Grapes were collected from 9 year old vineyards ( 6 ha). The distance between the rows was $2.4 \mathrm{~m}$ and the distance between the vines was $0.9 \mathrm{~m}$, at $560-580 \mathrm{~m}$ altitude of the vineyard. Grapes were harvested early in the morning and placed in crates.

\subsection{Winemaking}

Harvested Vranec grapes ( $450 \mathrm{~kg}$ ) were transported to the wine cellar of ELENOV Winery, Demir Kapija, R. Macedonia. Grapes were processed using electrical inox crusher/destemmer. The crushed grapes were divided into 3 lots: 1 - control ' $\mathrm{C}$ ' ( $\mathrm{SO}_{2}$ and yeast), 2 - lot with enzyme ' $\mathrm{E}$ ' ( $\mathrm{SO}_{2}$, yeast and enzyme) and 3 - lot with oak chips ' $\mathrm{OC}$ ' $\left(\mathrm{SO}_{2}\right.$, yeast and oak chips) (150 kg for each lot), and collected in plastic fermentation vessels $(200 \mathrm{~L})$, which were supplied with $\mathrm{SO}_{2}$ at a $50 \mathrm{mg} / \mathrm{L}$ concentration. $\mathrm{SO}_{2}$ was added in a form of $5 \%$ sulphurous acid.

After addition of $\mathrm{SO}_{2}$, a commercial pectinases enzyme preparation, Lallzyme EX-V, classified as Xn R42, with EC number EL016-22-40, obtained from Lallemand (Montreal, Canada) was added to the second lot $(2 \mathrm{~g} / \mathrm{hL})$. After two hours, commercial yeast Lalvin ICV-D254, S. cerevisiae, supplied from Lallemand (Montreal, Canada) was applied in all three lots in order to start the fermentation. Yeast was prepared by rehydration $(25 \mathrm{~g} / \mathrm{hL})$ in must, followed by the addition of nutrients, $25 \mathrm{~g} / \mathrm{hL}$ (GO-FARM, obtained from Lallemand, Canada). The third lot was processed with addition of oak chips (French Oak, Erbslöh, Geisenheim, Germany) in dose of $2 \mathrm{~g} / \mathrm{L}$.

After addition of $\mathrm{SO}_{2}$, yeast, enzyme and oak chips, grape mash was macerated for 4, 7, 14 and 30 days. In fact, a portion of wine was separated from the pomace from each of the three lots after 4 days of maceration, after 7, 14 and 30 days of maceration, and each portion was placed in a $5 \mathrm{~L}$ glass vessel, thus obtaining 12 samples for analysis ( 4 from each lot). During the alcoholic fermentation, mechanical "pumping over" was applied for all lots, three times a day. Wines were stabilized at $-15^{\circ} \mathrm{C}$ for a period of three days to induce tartaric stability, bottled and stored in a cellar at 6$8^{\circ} \mathrm{C}$. Analyses of the aroma profile were performed after ageing of one year.

The labels for the obtained wines are given in Table 1.

Table 1

Labels of Vranec wine samples prepared under different vinifications.

\begin{tabular}{llll}
\hline Wines & 1 & 2 & 3 \\
Days of maceration & Control & Wine with enzyme & Wine with oak chips \\
\hline 4 & $4 \mathrm{~d}-\mathrm{C}$ & $4 \mathrm{~d}-\mathrm{E}$ & $4 \mathrm{~d}-\mathrm{OC}$ \\
7 & $7 \mathrm{~d}-\mathrm{C}$ & $7 \mathrm{~d}-\mathrm{E}$ & $7 \mathrm{~d}-\mathrm{OC}$ \\
14 & $14 \mathrm{~d}-\mathrm{C}$ & $14 \mathrm{~d}-\mathrm{E}$ & $14 \mathrm{~d}-\mathrm{OC}$ \\
30 & $30 \mathrm{~d}-\mathrm{C}$ & $30 \mathrm{~d}-\mathrm{E}$ & $30 \mathrm{~d}-\mathrm{OC}$ \\
\hline
\end{tabular}




\subsection{HS-SPME-GC-MS analyses}

An automated headspace solid-phase microextraction (HSSPME) combined with gas chromatography-mass spectrometry (GC-MS) is highly efficient separation technique for extraction and separation of wine aroma compounds, as already used by some authors (Barros et al., 2012). In this study, this technique was used for the extraction and enrichment of the volatile compounds from the investigated wine samples, followed by GC-MS analysis of the aroma compounds. For the headspace analysis, $500 \mu \mathrm{L}$ of wine were transferred into a $20 \mathrm{~mL}$ headspace vial. Before closing the vial, the headspace was flushed with nitrogen. The following SPME fibre was used: DVB/Carboxen/PDMS 50/30, $2 \mathrm{~cm}$ stable flex (SupeIco, Bellfonte, USA). Sampling was performed using a CTC Combi PAL sampler (CTC Analytics, Switzerland). Prior to the extraction of the volatiles, the samples were equilibrated in the oven of the autosampler at $40{ }^{\circ} \mathrm{C}$ for $5 \mathrm{~min}$. Samples were stirred thoroughly using a glass coated magnetic stirrer. The SPME fibre was exposed into the headspace of the sample for $20 \mathrm{~min}$ at $40{ }^{\circ} \mathrm{C}$. Immediately after the exposure, the fibre was transferred to the GC-injector for thermo-desorption at $270^{\circ} \mathrm{C}$.

All GC-MS analysis were performed on an Agilent system (GC 7890, MS 5975c VL MSD) using an analytical column of medium polarity (HP5MS, $30 \mathrm{~m} \times 0,25 \mathrm{~mm} \times 1 \mu \mathrm{m}$, Agilent Technologies) with the following temperature program: $-10^{\circ} \mathrm{C}$ for $1 \mathrm{~min}$ with a temperature ramp of $8{ }^{\circ} \mathrm{C} \mathrm{min}^{-1}$ up to $270{ }^{\circ} \mathrm{C}$ (holding time $1 \mathrm{~min}$ ). Cryo-focussing by blowing liquid nitrogen into the GC-oven was applied to reach the start temperature of $-10^{\circ} \mathrm{C}$ with the aim to obtain higher resolution for compounds with very high volatility. The mass selective detection was performed in the scan mode (20-300 amu, EI (70 eV), detector temperature $230^{\circ} \mathrm{C}$ ).

Identification of the volatile compounds was based on comparison of the obtained mass spectra with the mass spectra from literature and MS databases as well as the calculation of linear temperature programmed retention indices (LRI) according to Farkas, Le Quere, Maarse, and Kovac (1994). Measured LRI were compared to data from a retention index database (SKAF Flavour database). For identification of the partial overlaid ion peaks, GCMS extracted ion chromatograms (EICs) were used. The relative amount of each volatile compound was calculated using the peak area of each compound in EICs.

\subsection{Statistical analysis}

Each wine was analysed in four replicates. Results were statistically treated by calculation of means, standard deviation and relative standard deviation. In addition, the ANOVA test of Student-Newman-Keuls of multiple comparisons of mean values was applied to the results to ascertain possible significant differences in the result for each aroma compound between the studied wines using GraphPad InStat Software (Version 3.05, USA). Significant difference was statistically considered at the level of $p<0.05$. In order to reveal any grouping of the Vranec wines produced with different oenological practices, based on the composition of volatile compounds, as well as to identify the constituents that are the chemotypical factors, the twelve samples were analysed using principal component analysis with the software package TANAGRA 1.4.28 (Lyon, France).

\section{Results and discussion}

The aroma profile of the Vranec wines obtained with different oenological practices, including different maceration time $(4,7$, 14 and 30 days), addition of enzyme and oak chips during fermentation, was determined using HS-SPME-GC-MS technique as described above. In this study, a total of 63 individual aroma compounds have been identified in the Vranec samples. Some of them were previously identified in Vranec wine (Ivanova et al., 2012), but most of them are reported for the first time here, in the wines from this variety. Different families of aroma compounds were considered: alcohols, esters, fatty acids, aldehydes, ketones, sulphur compounds and other compounds. The identified compounds, grouped in chemical classes are presented in Table 2 and a total ion chromatogram of one sample of Vranec wine ( $7 d-C)$ is shown in Fig. 1. For quantitative purposes, the relative amounts of 63 volatile compounds from the different groups detected in the twelve Vranec wines were calculated from the peak areas in extracted ion chromatograms for each compound. Furthermore, the relative amounts of total alcohols, esters, fatty acids, aldehydes and ketones were also calculated, as a sum of the relative amounts (peak areas in EIC) of each compound belonging to the corresponding chemical class.

\subsection{Alcohols}

Alcohols are compounds formed during the alcoholic fermentation as products of the yeast metabolism. In our study, 18 alcohols have been identified in the analysed Vranec wines (Table 2). This volatile fraction was mainly composed of five compounds present in highest amount: isoamyl alcohol, 2-methyl-1-butanol, phenylethyl alcohol, isobutyl alcohol and 1-hexanol, which is in agreement with literature data (Jiang \& Zhang, 2010; Patel \& Shibamoto, 2003; Schreier, Drawert, \& Junder, 1976). These compounds are usually formed by the yeast, from the sugars or amino acids present in the grape mash (Ivanova et al., 2012). In addition, considerable amounts of 2,3-butanediol, 1-propanol and 1-heptanol were also present in the wines. Fig. 2a shows the relative amount of total alcohols found in Vranec wines produced by different oenological practices.

Investigating the effect of maceration time, several observations were made. As indicated in Fig. 2a, maceration time evoked increased content of alcohols, observing highest amount in two wine lots (control wine and wine containing oak chips) macerated for 7 days, and highest amount in the wine macerated for 14 days, treated with enzyme, followed by slight decrease in all wines (yet not significantly different, $p>0.05$ ) during the maceration. In accordance to the changes of total alcohols, isoamyl alcohol, the most abundant individual alcohol, increased from fourth to seventh day of maceration $(p<0.05)$ in control wine $(C)$ and in wine with oak chips (OC), while enzymatically treated wine (E) contained highest amount after 14 days of maceration. Afterwards, isoamyl alcohol remained stable in all wines (Table 3 ). The relative amounts of isobutyl alcohol and 1-hexanol slightly increased (not significantly different, $p>0.05$ ) from fourth to fourteen day of maceration, followed by slight decrease in the wine macerated for 30 days. Concerning phenylethyl alcohol, the most important phenol-derived alcohol, similar observations were noticed. Thus, its relative amount significantly increased at 14 th day of maceration in the control sample, while in the wines with enzyme and chips, the highest content was observed in wines macerated for 7 days. Afterwards, there was no significant difference of phenylethyl alcohol $(p>0.05)$ in the other wines. In fact, the extraction of aroma compounds from grapes into the must is mainly a diffusion process, but the presence of enzyme, oak chips as well as longer maceration time could contribute to a more efficient extraction of aroma compounds into the juice. Thus, during the skin maceration, the content of alcohols increased which is in agreement with previous studies (Rodriguez-Bencomo, Mendez-Siverio, Pérez-Trujillo, \& Cacho, 2008; Selli, Cabaroglu, Canbas, Erten, \& Nurgel, 2003). The observed small decrease of alcohols in wines macerated for longer maceration time (14 and 30 days) was in agreement with the 
Table 2

Aroma compounds identified in Vranec wine samples produced under different vinifications.

\begin{tabular}{|c|c|c|c|}
\hline No. & Compounds & $t_{R} / \mathrm{min}$ & LRI \\
\hline \multicolumn{4}{|c|}{ Alcohols } \\
\hline 1 & 1-Propanol & 7.688 & 1018 \\
\hline 3 & Isobutyl alcohol & 9.406 & 1053 \\
\hline 5 & 1-Butanol & 10.317 & 1082 \\
\hline 6 & 3-Methyl -3-buten-2-ol & 10.862 & 1105 \\
\hline 10 & Isoamyl alcohol & 12.288 & 1140 \\
\hline 11 & 2-Methyl-1-butanol & 12.339 & 1150 \\
\hline 14 & 1-Pentanol & 12.977 & 1173 \\
\hline 17 & 2,3-Butanediol & 13.303 & 1145 \\
\hline 18 & 1,3-Butanediol & 13.527 & 1200 \\
\hline 21 & 4-Methyl-1-pentanol & 14.634 & 1243 \\
\hline 23 & 3-Methyl-1-pentanol & 14.854 & 1251 \\
\hline 26 & 3-Hexen-1-ol & 15.14 & 1268 \\
\hline 27 & 1-Hexanol & 15.4 & 1277 \\
\hline 37 & 1-Heptanol & 17.679 & 1341 \\
\hline 38 & 1-Octen-3-ol & 17.915 & 1342 \\
\hline 45 & 2-Ethyl hexanol & 18.968 & 1443 \\
\hline 48 & 1-Octanol & 19.805 & 1438 \\
\hline 51 & Phenylethyl alcohol & 20.919 & 1555 \\
\hline \multicolumn{4}{|c|}{ Esters } \\
\hline 2 & Ethyl acetate & 8.96 & 1033 \\
\hline 7 & Propanoic acid, ethyl ester & 11.509 & 1108 \\
\hline 8 & Acetic acid, propyl ester & 11.582 & 1113 \\
\hline 12 & Propanedioic acid, dimethyl & 12.565 & 1157 \\
\hline 13 & Propanoic acid, 2-methyl-ethyl ester & 12.751 & 1167 \\
\hline 15 & Acetic acid, 2-methylpropyl ester & 13.112 & 1176 \\
\hline 19 & Butanoic acid, ethyl ester & 13.767 & 1233 \\
\hline 24 & Butanoic acid, 2-methyl- ethyl ester & 14.978 & 1253 \\
\hline 25 & Butanoic acid, 3-methyl- ethyl ester & 15.043 & 1258 \\
\hline 28 & 1-Butanol, 3-methyl-acetate & 15.586 & 1279 \\
\hline 29 & 1-Butanol, 2-methyl- acetate & 15.647 & 1245 \\
\hline 31 & Pentanoic acid, ethyl ester & 16.123 & 1302 \\
\hline 34 & Hexanoic acid, methyl ester & 16.686 & 1330 \\
\hline 35 & Butanoic acid, 3-hydroxy-ethyl ester & 16.939 & 1335 \\
\hline 41 & Hexanoic acid, ethyl ester & 18.303 & 1403 \\
\hline 42 & 3-Hexenoic acid, ethyl ester & 18.431 & 1404 \\
\hline 44 & Acetic acid, hexyl ester & 18.593 & 1429 \\
\hline 46 & 2-Hexenoic acid, ethyl ester & 19.262 & 1431 \\
\hline 47 & Ethyl 2-hydroxycaproate & 19.606 & 1436 \\
\hline 52 & Ethyl hydrogen succinate & 21.482 & 1560 \\
\hline 54 & Butanedioic acid, diethyl ester & 21.891 & 1549 \\
\hline 55 & Octanoic acid, ethyl ester & 22.245 & 1609 \\
\hline 57 & Benzeneacetic acid, ethyl ester & 23.312 & 1657 \\
\hline 59 & Acetic acid, 2-phenylethyl ester & 23.554 & 1694 \\
\hline 60 & Nonanoic acid, ethyl ester & 24.037 & 1758 \\
\hline 62 & Decanoic acid, ethyl ester & 25.725 & 1827 \\
\hline 63 & $\begin{array}{l}\text { 1,2-Benzenedicarboxylic acid, bis 2-methylpropyl) } \\
\text { ester }\end{array}$ & 32.834 & 1736 \\
\hline \multicolumn{4}{|c|}{ Fatty acids } \\
\hline 16 & Butanoic acid & 13.193 & 1181 \\
\hline 20 & Iso-valeric acid & 14.543 & 1236 \\
\hline 22 & 2-Methyl-butanoic acid & 14.796 & 1246 \\
\hline 36 & Hexanoic acid & 17.628 & 1335 \\
\hline 53 & Octanoic acid & 21.59 & 1539 \\
\hline 58 & Nonanoic acid & 23.376 & 1667 \\
\hline 61 & n-Decanoic acid & 25.123 & 1794 \\
\hline \multicolumn{4}{|c|}{ Aldehydes and ketones } \\
\hline 4 & 3-Methyl-butanal & 9.986 & 1064 \\
\hline 9 & 3-Hydroxy-2-butanone, & 11.708 & 1138 \\
\hline 32 & n-Heptanal & 16.2 & 1317 \\
\hline 40 & 2-Octanone & 18.183 & 1350 \\
\hline 43 & Octanal & 18.458 & 1410 \\
\hline 49 & 5-Nonanone & 19.913 & 1506 \\
\hline 50 & Nonanal & 20.551 & 1525 \\
\hline 56 & Decanal & 22.502 & 1654 \\
\hline \multicolumn{4}{|c|}{ Sulphur compounds } \\
\hline 39 & 3-(methylthio)-1-propanol & 17.959 & 1347 \\
\hline \multicolumn{4}{|c|}{ Other compounds } \\
\hline 30 & Oxime-, methoxy-phenyl- & 15.873 & 1251 \\
\hline 33 & Butyrolactone & 16.531 & 1324 \\
\hline
\end{tabular}

LRI-linear retention indices. literature (Redeka, Lukić, \& Peršurić, 2012) and it could be due to fixation to macromolecules or treatments applied, since addition of enzyme and oak chips could influence better clarification of the wine decreasing the higher alcohols content.

According to Romano et al. (2003), S. cerevisiae is characterized by high production of isoamyl alcohol, as it was also observed in Vranec wines fermented with this yeast strain, regardless the applied oenological treatments. Concerning the applied oenological practises, including addition of enzyme and oak chips during fermentation, wines with chips (macerated for 4, 7 and 30 days) showed highest content of total alcohols. The obtained results were in agreement with literature data (Pérez-Coello et al., 2000; Rodríguez-Bencomo et al., 2010) where higher concentration of alcohols in wines fermented with oak chips was also found compared to the control wines. Phenylethyl alcohol and isobutyl alcohol were present in higher relative amounts in the wines fermented in the presence of the oak chips than in the control wines, regardless the maceration time (Table 3 ), while for the isoamyl alcohol and 2-methyl-1-butanol there was no significant difference observed $(p>0.05)$ between the wines (C, E and OC). Since higher alcohols are products of the yeast metabolism, higher fermentation yields could be obtained when the grape must is fermented in presence of chips, because the chips acts as a carrier for the yeast cells exerting an effect similar to that of immobilized cells (Rodríguez-Bencomo et al., 2010). Regarding the influence of the enzyme, the relative amounts of isoamyl alcohol and total alcohols, as well as the amounts of the other alcohols in the wines produced with enzymatic treatment, were very similar and not significantly different $(p>0.05)$ from the control wines indicating that enzyme addition during maceration does not influence the content of alcohols.

\subsection{Esters}

Esters are another group of volatiles that greatly influence the wine aroma. It was shown that Vranec wines were rich in esters since 29 esters were identified. Among them, ethyl acetate was the dominant compound from this fraction, followed by butanedioic acid diethyl ester, 1-butanol-3-methyl acetate and propanoic acid ethyl ester. Furthermore, considerable amounts of ethyl esters, such as, butanoic acid ethyl ester, octanoic acid ethyl ester, propanoic acid-2-methyl-ethyl ester, butanoic acid-3-methyl-ethyl ester, and other esters such as ethyl hydrogen succinate and 1-butanol-2-methyl-acetate were detected in the wines.

Skin contact resulted in increase of the relative amount of esters in the control wine and the wine treated with enzyme from fourth to seventh day of maceration, and afterwards, the content of esters remained stable $(p>0.05)$. The highest level of esters in wines treated with oak chips was reached in the wine macerated for 4 days (Fig. 2b). Further increasing of maceration time in this wine led to a slight decrease in their content. The relative amounts of the most abundant ester, ethyl acetate, were similar in the wines macerated for different days, observing no significant differences also in the wines containing enzyme and oak chips during maceration. Butanedioic acid diethyl ester reached highest content in the control wine macerated for 4 days, followed by decreasing of the amount during maceration. In the wines treated with enzyme and oak chips, this ester significantly increased, reaching highest content in the wines macerated for 7 and 14 days, respectively (Table 3). Longer maceration time also caused increasing of the relative amount of hexanoic acid ethyl ester in the control wine and enzymatically treated wine, while, in the wine with oak chips, highest content was observed in the wine macerated for 4 days, followed by significant decrease until seventh day of maceration $(p<0.05)$, remaining stable in the wines macerated for 14 and 


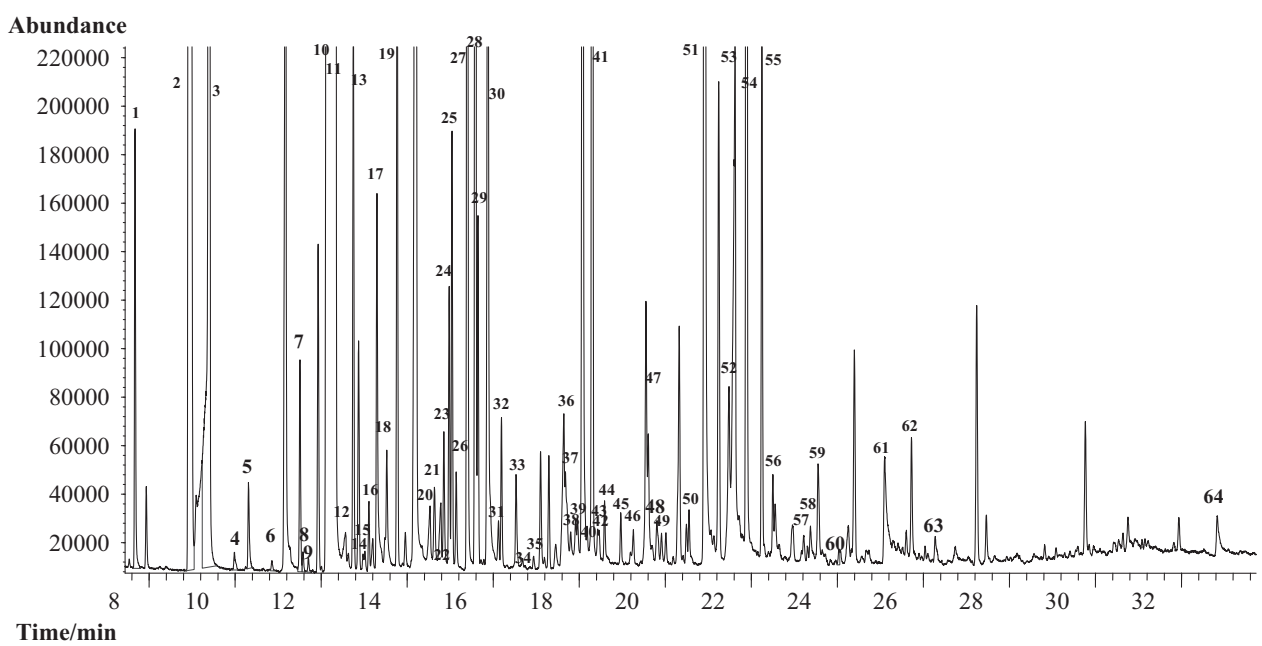

Fig. 1. Total ion chromatogram of the aroma compounds found in Vranec wine (sample 7d-C). Peak numbers refer to the compounds listed in Table 2.

30 days. According to the literature data, maceration time does not directly affect the content of esters in wine (Rapp, Günter, \& Ullemeyer, 1985) and longer maceration time could even generate decrease of acetates of higher alcohols and ethyl esters of fatty acids, as it was also observed for some esters in this study, probably as a result of nonenzymatic hydrolysis.

Concerning the effect of enzyme and oak chips, it was observed that wines with chips present during the wine fermentation, macerated for 4 days, showed highest amounts of esters. Thus, propanoic acid ethyl ester, butanoic acid ethyl ester, pentanoic acid ethyl ester and hexanoic acid ethyl ester were present in higher relative amounts in the wines fermented with oak chips, while the effect of enzyme was not significant (Table 3 ).

Esters are very important components of wine aroma, making positive contribution to the general quality of wine providing delicate "fruity" and "floral" odours, affecting the sensory properties and aromatic finesse of wines. Their formation and content in wine mainly depend on the number of alcohols and acids. Since wine contains a large number of different alcohols and acids that participate in reactions of esterification, the number of formed esters in wine is expected to be high, as it was also observed in this study. Furthermore, our results demonstrate that maceration time and oenological practices to some extent affect the formation and variation of various esters contributing to the wine aroma.

\subsection{Fatty acids}

Within the family of fatty acids, 7 compounds were detected in Vranec wines, including butanoic acid, iso-valeric acid, 3-methylbutanoic acid, 2-methyl-butanoic acid, hexanoic, octanoic, nonanoic and decanoic acids. Among them, octanoic acid was the dominant one, followed by hexanoic acid. The relative amounts of fatty acids (Fig. 2c) increased from forth to seventh day of maceration in control wine and enzyme-treated wine, while the third lot, wine containing oak chips, showed highest amount after 4 days of maceration, followed by decrease $(p>0.05)$. As previously shown, the production and presence of fatty acids depends on the composition of grape must and fermentation conditions (García-Carpintero, Gómez Gallego, Sánchez-Palomo, \& González Viñas, 2012; Schreier \& Jennings, 1979). Thus, these compounds could be formed by anabolic pathways in yeast or could arise via $\beta$-oxidation of higher fatty acids. Fatty acids could also form esters that could be a reason for decreasing of their content during the maceration time, especially evident for the wines containing oak chips. Furthermore, during the maceration and alcoholic fermentation, fatty acids could be used by the yeast as a carbon source evoking decline of their amounts. Usually, the presence of fatty acids in wine is related to unpleasant odours, even these compounds don't have a direct negative effect on the favour of the wines since they are present in low concentrations.

Addition of oak chips during fermentation of 4 and 30 days produced higher relative amounts of fatty acids, including the most abundant compounds, octanoic and hexanoic acids, while, no significant differences were observed between these compounds in the wines macerated for 7 and 14 days. Similar results were found by Rodríguez-Bencomo, Ortega-Heras, and Pérez-Magariño (2010) who also found higher concentrations of hexanoic and octanoic acid in red wines fermented with oak chips. In our study, no significant differences were observed related to the use of enzyme during fermentation, which is in agreement with the literature (Rodríguez-Bencomo, Mendez-Siverio, \& Perez-Trujillo, 2010).

\subsection{Carbonyl compounds}

Among carbonyl compounds, $n$-heptanal and decanal were the main compounds present in highest relative amount in the wines macerated for 4 days, followed by slight decrease of the content during the maceration (Fig. 2d). In fact, these compounds are formed by oxidation of alcohols to aldehydes or ketones. Furthermore, carbonyl compounds can participate in further oxidation reactions forming carboxylic acids, which could provoke decrease of their content during fermentation, as it was observed here. Addition of oak chips in the wine produced higher content of carbonyl compounds, while no effect related to the enzyme was observed, except for the wine macerated for 4 days, where wine with enzyme presented significantly lower amount compared to the control wine.

\subsection{Other compounds}

Among the other volatile compounds found in wines, one sulphur compound and one lactone have been detected in the Vranec wines, 3-(methylthio)-1-propanol and butyrolactone, respectively. The relative amount of both compounds increased with maceration time. It was observed that the enzymatically treated wine contained the lowest amount among the control wine and wine with oak chips. An effect of the addition of enzyme and oak chips during fermentation was not observed for these two compounds. 

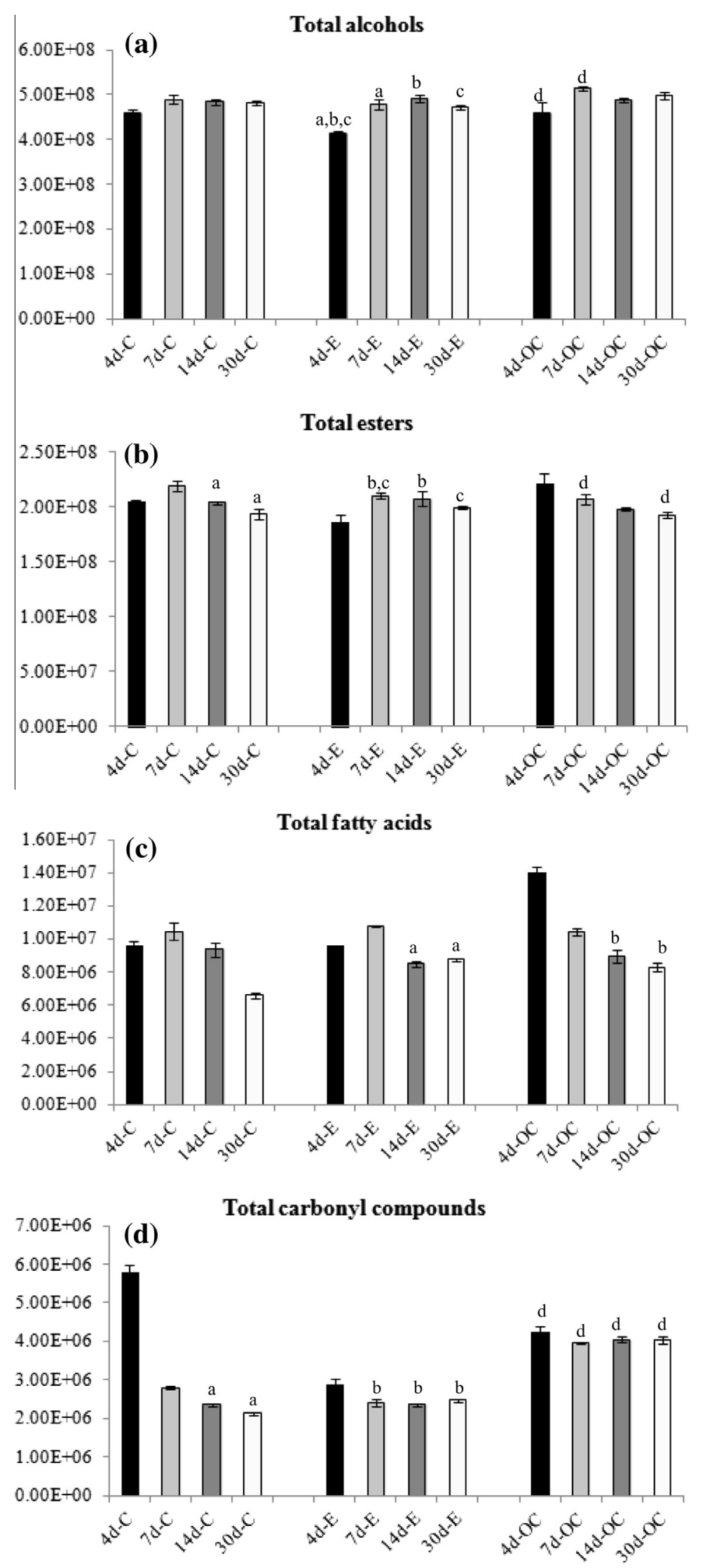

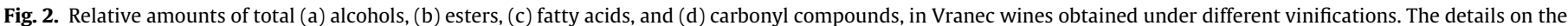

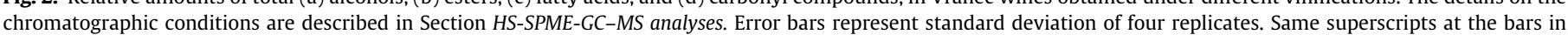

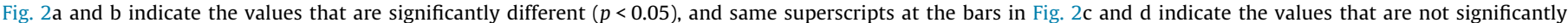
different $(p<0.05)$. Labels of the wines correspond to ones in Table 1 . 
According to Moreira et al. (2002), the formation of sulphur compounds in wine is related to yeast metabolism and nitrogen composition of must. 3-(methylthio)-1-propanol is one of the less volatile sulphuric compounds present in wines, which could contribute to a cauliflower aroma if present in a concentration above its threshold value. The other detected compound, butyrolactone, is frequently found among the wine volatiles. It does not play an important role in the sensorial properties of wine since it is not present in considerable amounts to influence the wine aroma. Butyrolactone is formed from 4-hydroxybutanoic acid by internal esterification.

\subsection{Principal component analysis}

For extracting useful information from the results for aroma compounds in Vranec wines produced with different vinifications, Principal Component Analysis (PCA) was applied using the data for the relative amount of each identified compound obtained from the corresponding peak areas in the extracted ion chromatograms. PCA was performed in order to evaluate the effect of each parameter (maceration time of 4, 7, 14 and 30 days, addition of enzyme and oak chips during fermentation) on the aroma profile of the analysed wines and to identify the volatile compounds that best discriminate the wines.

The first two principal components, PC1 and PC2, accounted for $52.19 \%$ of the total variance (33.99\% for PC1 and $18.29 \%$ for PC2). The projection of the Vranec wine samples on the first two principal components showed a clear separation according to the maceration time (Fig. 3a). Thus, wines were mainly divided and separated in three groups: wines macerated for 4 days formed one group (clearly separated from the other wines and located in the positive part of PC1), the wines macerated for 7 days formed the second group, located around the origin and along PC2, and the third group was composed of wines macerated for 14 and 30 days, located in the negative part of PC1. In this respect, $\mathrm{PC} 1$ was mostly related to the maceration time. The principal components responsible for the differences in the volatile composition of the wines produced with different practices were determined and presented in the scatter plot in Fig. 3b. Thus, the responsible components for the separation of wines were:

- The alcohols: isobutuy alcohol (3); 1-pentanol (14); 1,3butanediol (18); 1-hexanol (27); 1-heptanol (37) and

- Esters: propanoic acid 2-methyl-ethyl ester (13); butanoic acid ethyl ester (19); butanoic acid 2-methyl-ethyl ester (24); butanoic acid 3-methyl-ethyl ester (25) and 1-butanol 3-methyl-acetate (28).

They were negatively correlated to PC1 and were specific for the wines macerated for 14 and 30 days. Furthermore, parameters that discriminate wines macerated for 7 days were: acetic acid propyl ester (8); acetic acid hexyl ester (44) and 2-methylbutanoic acid (22).

With regard to $\mathrm{PC} 2$, further distinction between the wines appeared in correlation to the enzyme and oak chips treatments. Thus, wines treated with oak chips were located in the positive part of $\mathrm{PC} 2$, and the control wines and enzymatically treated wines were placed in the negative part of PC2 (with exception of wine $7 d-C$ ), as shown in Fig. 3a, which means that PC2 was related to the oak chips treatment. The main principal components responsible for the differences of wines with regard to the different practices were isobutyl alcohol (3), phenylethyl alcohol (51); 1-propanol (1); 1-butanol (5); butyrolactone (33); propanoic acid, ethyl ester (7); butanoic acid ethyl ester (19), pentanoic acid ethyl ester (31) and hexanoic acid ethyl ester (41), specific for the wines with oak chips addition. 


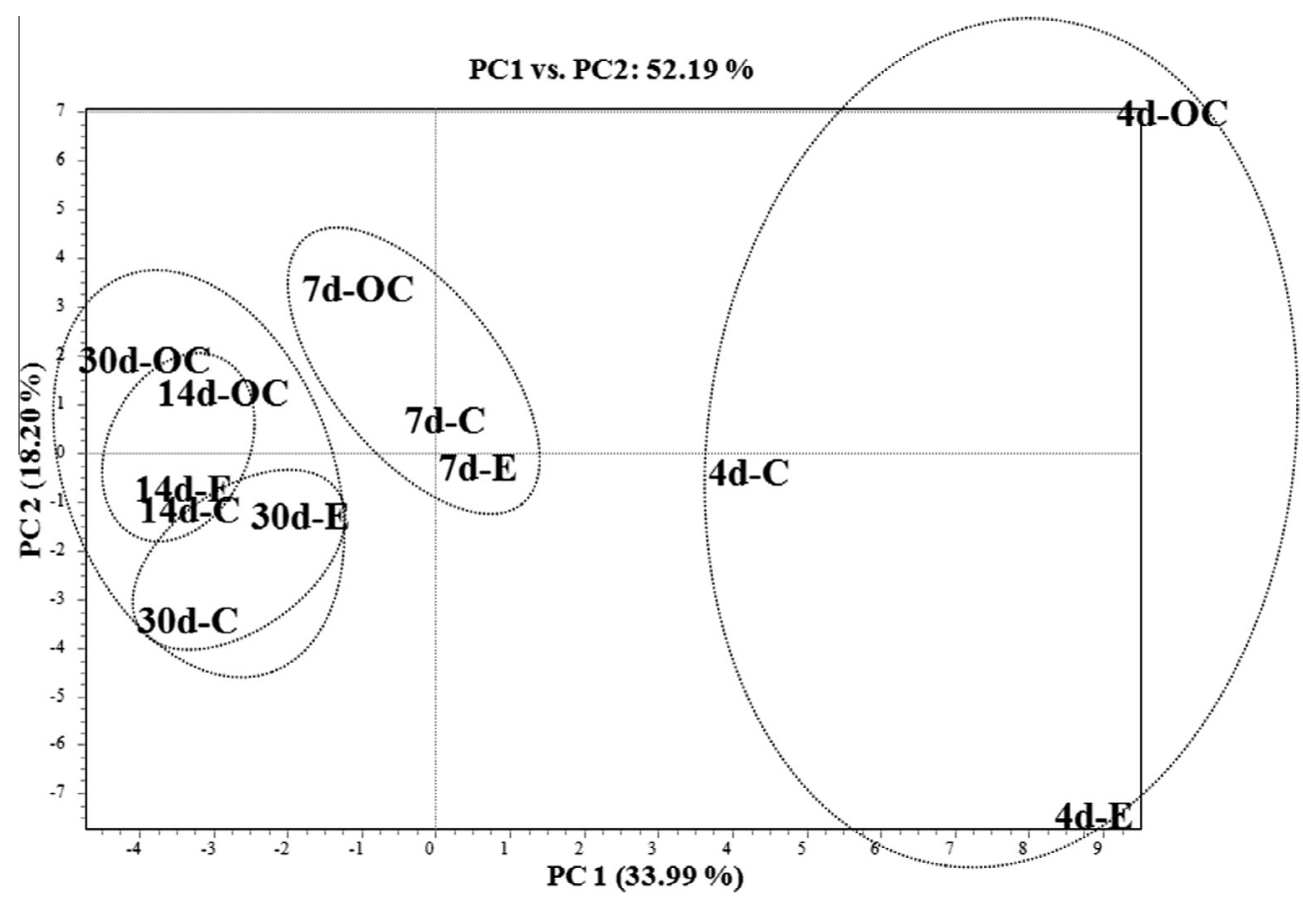

Fig. 3a. Classification of Vranec wines analysed in function of PC1 and PC2, for all the analysed variables. Labels of the wines correspond to ones in Table 1.

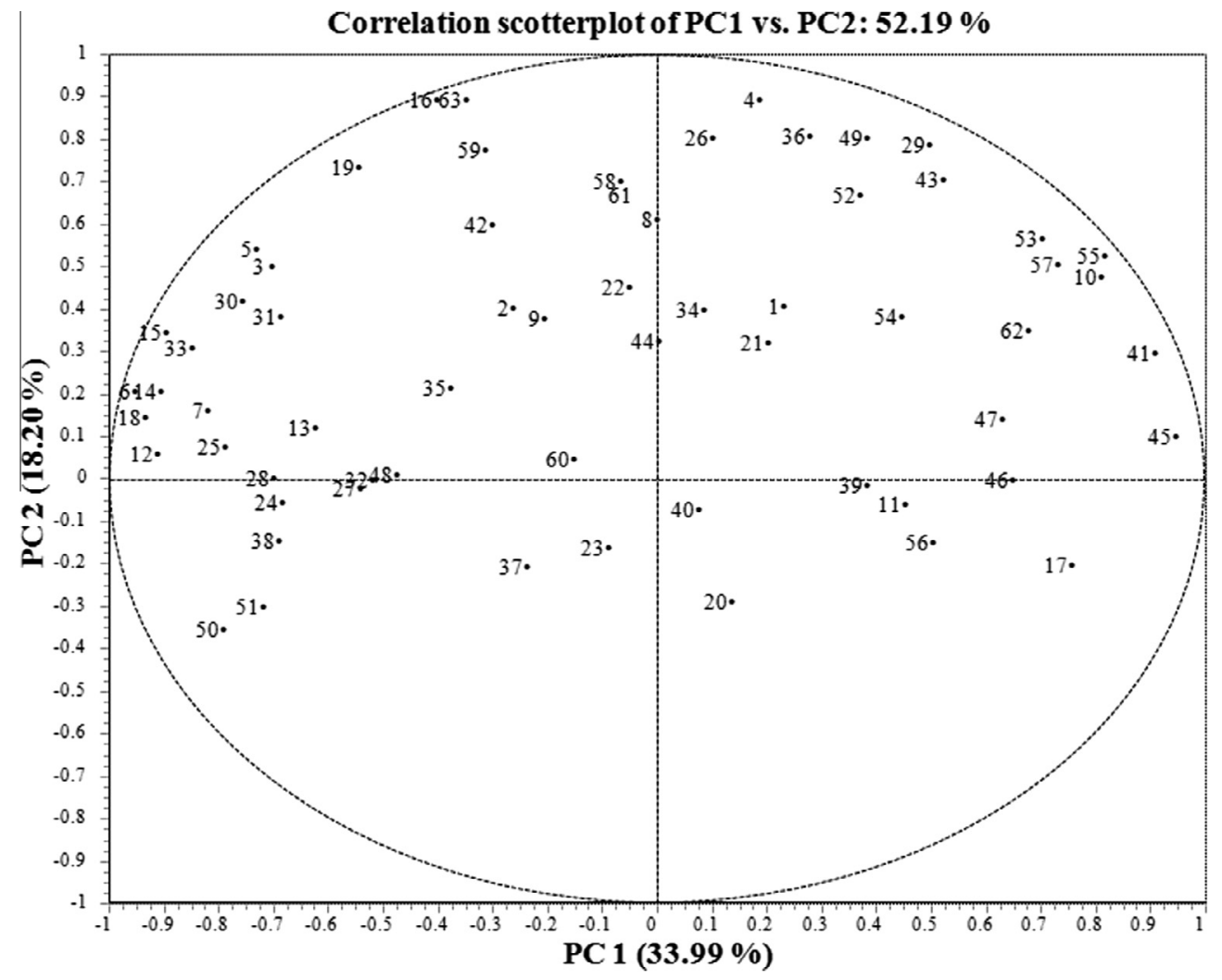

Fig. 3b. PCA loadings of all analysed compounds. Peak numbers refer to the compounds listed in Table 2.

\section{Conclusions}

A total of 63 individual aroma compounds have been detected in twelve Vranec wine samples prepared under controlled vinification conditions using HS-SPME-GC-MS technique. Vranec wines presented complex aroma profile rich in different families of aroma compounds: esters, alcohols, fatty acids, aldehydes and ketones. Maceration time and addition of oak chips influenced the aroma profile. The results showed that maceration time affects the content of aroma compounds leading to increased relative 
amounts of volatile compounds from the fourth to seventh day of maceration. The presence of oak chips during the fermentation enhanced the formation of volatile compounds, such as phenylethyl alcohol, isobutyl alcohol, propanoic acid ethyl ester, butanoic acid ethyl ester, pentanoic acid ethyl ester and hexanoic acid ethyl ester. No significant effect of the addition of enzyme to the volalatile compounds in Vranec wines was observed.

\section{Acknowledgements}

This work was supported by a grant from the CEEPUS, CII-HU0010-03-0809 Network, covering the study stay of V.I.P. at the Institute of Analytical Chemistry and Food Chemistry, Graz University of Technology, Graz, Austria, where the analyses were performed. Gratitude is also expressed to Elenov winery for providing capacities for production the experimental wines.

\section{References}

Armada, L., Fernández, E., \& Falqué, E. (2010). Influence of several enzymatic treatments on aromatic composition of white wines. LWT - Food Science and Technology, 43, 517-1525.

Barros, E. P., Moreira, N., Pereira, G. E., Leite, S. G. F., Rezende, C. M., \& de Pinho, P. G. (2012). Development and validation of automatic HS-SPME with a gas chromatography-ion trap/masss pectrometry method for analysis of volatiles inwines. Talanta, 101, 177-186.

Bautista-Ortín, A. B., Martínez-Cutillas, A., Ros-García, J. M., López-Roca, J. M., \& Gómez-Plaza, E. (2005). Improving colour extraction and stability in red wines: The use of maceration enzymes and enological tannins. International Journal of Food Science and Technology, 40, 867-878.

Bozalongo, R., Carrillo, J. D., Fernándet Torroba, M. A., \& Tena, M. T. (2007). Analysis of French and American oak chips with different toasting degrees by headspace solid-phase microextraction-gas chromatography-mass spectrometry. Journal of Chromatography, 1173, 10-17.

Bureau, S., Razungles, A., \& Baumes, R. (2000). The aroma of muscat of Frontignan grapes: Effect of the light environment of vine or bunch on volatiles and glycoconjugates. Journal of the Science of Food and Agriculture, 80, 2012-2020.

Castro-Vázquez, I., Pérez-Coello, M. S., \& Cabezudo, M. D. (2002). Effects of enzyme treatment and skin extraction on varietal volatiles in Spanish wines made from Chardonnay, Muscat, Airén, and Macabeo grapes. Analytica Chimica Acta, 458, 39-44.

Farkas, P., Le Quere, J. L., Maarse, H., \& Kovac, M. (1994). The standard GC retention index library of flavour compounds. Developments in Food Science, 35, 145-149.

Garde Cerdán, T., Torrea Goñi, D., \& Ancín Azpilicueta, C. (2004). Accumulation of volatile compounds during ageing of two red wines with different composition. Journal of Food Engineering, 65, 349-356.

García-Carpintero, E. G., Gómez Gallego, M. A., Sánchez-Palomo, E., \& González Viñas, M. A. (2012). Impact of alternative technique to ageing using oak chips in alcoholic or in malolactic fermentation on volatile and sensory composition of red wines. Food Chemistry, 134, 851-863.

Hernandez Orte, P., Guitart, A., Ferreira, V., Gracia, J., \& Cacho, J. (1998). Effect of maceration time and the addition of enzymes on the amino acid composition of musts and wines and its influence on wine aroma. Food Science and Technology International, 4, 407-418.

Ivanova, V., Dörnyei, Á., Márk, L., Vojnoski, B., Stafilov, T., Stefova, M., \& Kilár, F. (2011). Polyphenolic content of Vranec wines produced by different vinification conditions. Food Chemistry, 124, 316-325.

Ivanova, V., Stefova, M., \& Chinnici, F. (2010). Determination of polyphenol contents in Macedonian grapes and wines assessed by standardized spectrophotometric methods. Journal of the Serbian Chemical Society, 75, 45-59.

Ivanova, V., Stefova, M., Vojnoski, B., Stafilov, T., Bíró, I., Bufa, A., et al. (2013). Volatile composition of Macedonian and Hungarian wines assessed by GC-MS. Food and Bioprocess Technology, 6, 1609-1617.
Ivanova, V., Vojnoski, B., \& Stefova, M. (2012). Effect of winemaking treatment and wine aging on phenolic content in Vranec wines. Journal of Food Science and Technology, 49, 161-172.

Jackson, D. I., \& Lombard, P. B. (1993). Environmental and management practices affecting grape composition and wine quality - a review. American Journal of Enology and Viticulture, 44, 409-430.

Jiang, B., \& Zhang, Z. (2010). Volatile compounds of young wines from Cabernet Sauvignon, Cabernet Gernischet and Chardonnay varieties grown in the Loess Plateau Region of China. Molecules, 15, 9184-9196.

Lee, S. H., Seo, M. J., Riu, M., Cotta, J. P., Block, D. E., Dokoozlian, N. K., et al. (2007). Vine microclimate and norisoprenoid concentration in Cabernet Sauvignon grapes and wines. American Journal of Enology and Viticulture, 58, 291-301.

Macedo, S., Fernandes, S., Lopes, J. A., de Sousa, H. C., Pereira, P. J., Carmelo, P. J., et al. (2008). Recovery of wine-must aroma compounds by supercritical $\mathrm{CO}_{2}$. Food and Bioprocess Technology, 1, 74-81.

Mendes, B., Gonçalves, J., \& Câmara, J. C. (2012). Effectiveness of high-throughput miniaturized sorbent and solid phase microextraction techniques combined with gas chromatography-mass spectrometry analysis for a rapid screening of volatile and semi-volatile composition of wines - A comparative study. Talanta, $88,79-94$.

Moreira, N., Mendes, F., Pereira, O., Guedes de Pinho, P., Hogg, T., \& Vasconcelos, I. (2002). Volatile sulphuric compounds in wines related to yeast metabolism and nitrogen composition of grape musts. Analytica Chimica Acta, 458, 157-167.

Patel, S., \& Shibamoto, T. (2003). Effect of 20 different yeast strains on the production of volatile components in symphony wine. Journal of Food Composition and Analysis, 16, 469-476.

Pérez-Coello, M. S., Sanchez, M. A., García, E., Gonzalez-Vinas, M. A., Sanz, J., \& Cabezudo, M. D. (2000). Fermentation of white wines in the presence of wood chips of American and French oak. Journal of Agricultural and Food Chemistry, 48, 885-889.

Perestrelo, R., Caldeira, M., Rodrigues, F., \& Câmara, J. (2008). Volatile flavour constituent patterns of Terras Madeirenses red wines extracted by dynamic headspace solid-phase microextraction. Journal of Separation Science, 31, $1841-1850$.

Rapp, A., Günter, M., \& Ullemeyer, H. (1985). Über Veränderungen der Aromastoffe während der Flaschenlagerung von Weißweinen der Rebsorte Riesling. Zeitschrift für Lebensmittel Untersuchung und Forschung, 180, 109-116.

Rayne, S., Sheppard, S., Di Bello, T., \& Eggers, N. J. (2011). Chromatic characteristics and optically derived compositional descriptors of micro-oxygenated wines from Vitis vinifera cv. merlot and cabernet sauvignon. Food and Bioprocess Technology, 4, 254-265.

Revilla, I., \& González-San José, M. L. (2003). Compositional changes during the storage of red wines treated with pectolytic enzymes: low molecular-weight phenols and flavan-3-ol derivative levels. Food Chemistry, 80, 205-214.

Rodriguez-Bencomo, J. J., Mendez-Siverio, J. J., Pérez-Trujillo, J. P., \& Cacho, J. (2008). Effect of skin contact on bound aroma and free volatiles of Listan blanco wine. Food Chemistry, 110, 214-225.

Rodríguez-Bencomo, J. J., Ortega-Heras, M., \& Pérez-Magariño, S. (2010). Effect of alternative techniques to ageing on lees and use of non-toasted oak chips in alcoholic fermentation on the aromatic composition of red wine. European Food Research and Technology, 230, 485-496.

Romano, P., Fiore, C., Paraggio, M., Caruso, M., \& Capece, A. (2003). Function of yeast species and strains in wine flavour. International Journal of Food Microbiology, 86 169-180.

Schreier, P., Drawert, F., \& Junder, A. (1976). Identification of volatile constituents from grapes. Journal of Agricultural and Food Chemistry, 24, 331-336.

Schreier, P., \& Jennings, W. G. (1979). Flavor composition of wines: A review. Critical Reviews in Food Science and Nutrition, 12, 59-111.

Selli, S., Cabaroglu, T., Canbas, A., Erten, H., \& Nurgel, C. (2003). Effect of skin contact on the aroma composition of the musts of Vitis vinifera L. cV. muscat of bornova and narince grown in Turkey. Food Chemistry, 81, 341-347.

Skinkis, P. A., Bordelon, B. P., \& Butz, E. M. (2010). Effects of sunlight exposure on berry and wine monoterpenes and sensory characteristics of Traminette. American Journal of Enology and Viticulure, 61, 147-156.

Zoecklein, B. W., Wolf, T. K., Marcy, J. E., \& Jasinski, Y. (1998). Effect of fruit zone leaf thinning on total glycosides and selected aglycone concentrations of Riesling (Vitis vinifera L.) grapes. American Journal of Enology and Viticulture, 49, 35-43. 